\title{
Ischaemia during exercise stress testing in an athlete with Wolff-Parkinson-White pattern
}

\author{
Arjun Kanwal 이, ${ }^{1}$ Katie M Bustin, ${ }^{2}$ Bronson Elizabeth Delasobera, ${ }^{3}$ Ankit B Shah ${ }^{2}$
}

\begin{abstract}
1 Internal Medicine, MedStar Union Memorial Hospital, Baltimore, Maryland, USA ${ }^{2}$ Sports \& Performance Cardiology Program, MedStar Heart and Vascular Institute, Baltimore, Maryland, USA ${ }^{3}$ Department of Sports Medicine, National Rehabilitation Hospital, Washington, DC, USA
\end{abstract}

\section{Correspondence to}

Dr Arjun Kanwal;

arjun.kanwal@medstar.net

Accepted 1 April 2020

\section{DESCRIPTION}

A 26-year-old asymptomatic competitive athlete was found to have a delta wave consistent with Wolff-Parkinson-White (WPW) pattern on a preparticipation screening ECG. His medical history was unremarkable and without risk factors for coronary artery disease. Physical examination was normal. An echocardiogram showed a structurally normal heart without evidence of hypertrophic cardiomyopathy or Ebstein's anomaly. He underwent maximal effort cycle ergometer stress testing using $50 \mathrm{~mm} / \mathrm{s}$ paper speed to minimise artefact and enhance visualisation of the delta wave as part of his risk stratification for sudden cardiac arrest/death. ${ }^{1}$ Stress testing revealed 4-5 mm ST segment depressions in II, III, aVF, V4 and V5 with a persistent delta wave at a heart rate at 186 beats/min. At a similar heart rate, there is abrupt loss of the delta wave and complete normalisation of the ST segments (figures 1 and 2). Intermittent delta waves were noted in recovery at 110 beats/min. CT coronary angiography revealed no evidence of coronary artery disease, myocardial bridging or anomalous coronary arteries. The patient was referred for electrophysiology study and ultimately underwent ablation of a left lateral accessory pathway. His postprocedure ECG was normal, and he has returned to competition with no complications.

WPW accounts for at least 3\% of sudden cardiac death/arrest in competitive athletes. ${ }^{2}$ Stress testing in athletes with WPW pattern is done to help risk

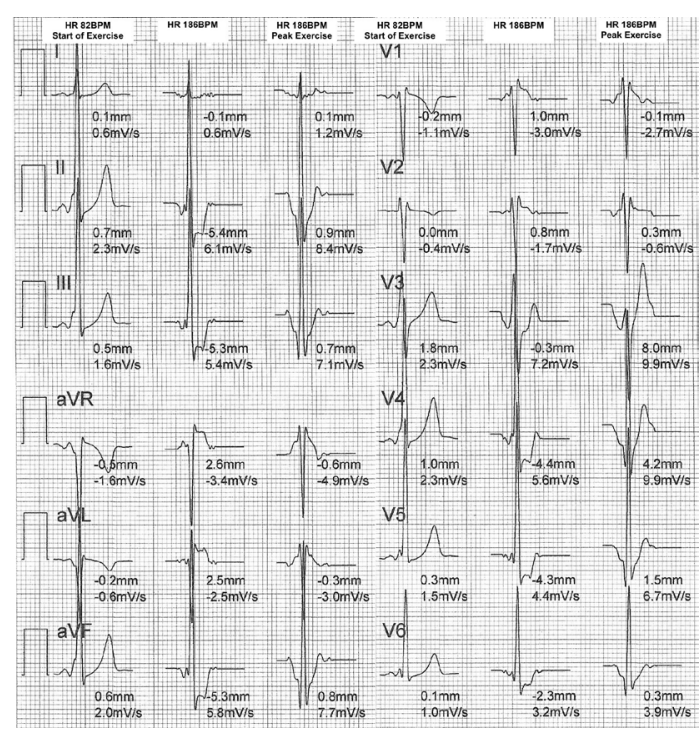

Figure 1 Computerised average of exercise test showing ST segment depressions in leads II, III, aVF, V4 and V5 concerning for ischaemia. HR, heart rate.

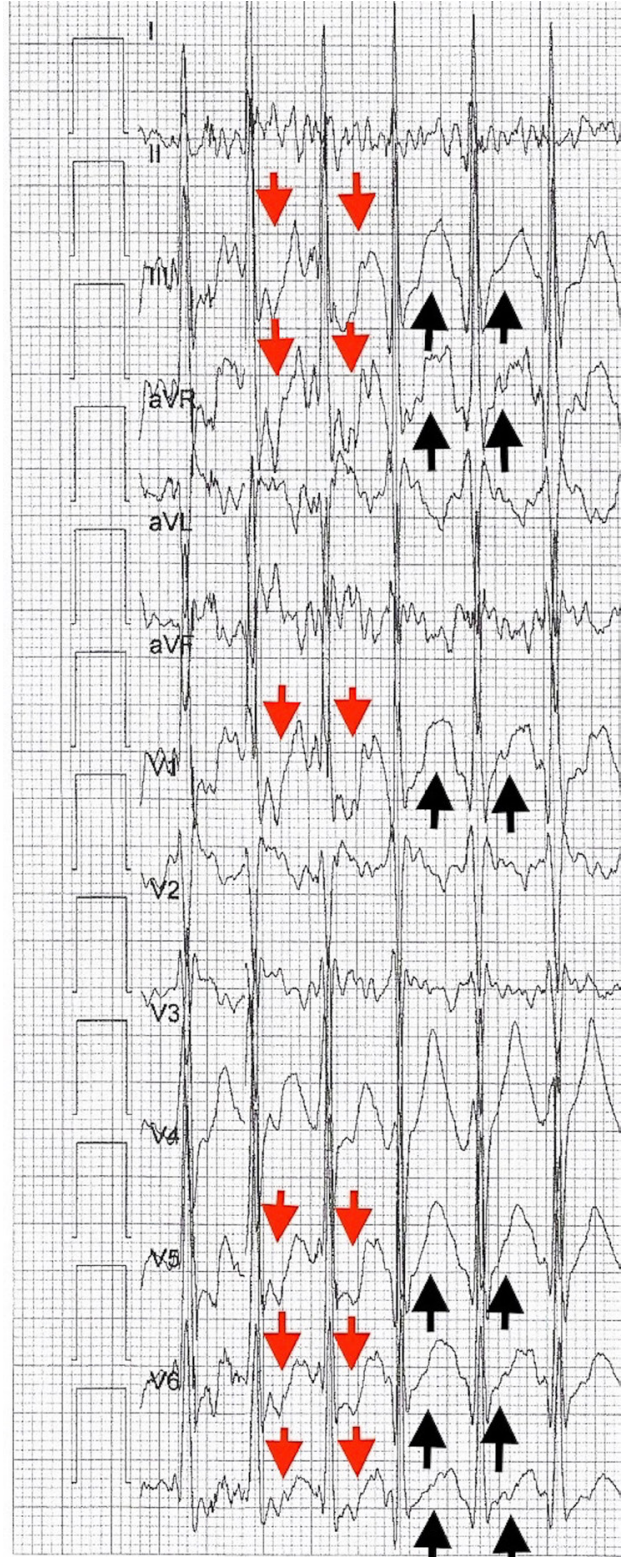

Figure 2 ECG during cycle ergometry exercise testing showing a persistent delta wave with $4-5 \mathrm{~mm}$ horizontal/ downsloping ST segment depressions in inferolateral leads at a heart rate of $186 \mathrm{bpm}$ (red arrows) and with abrupt loss of the delta wave that coincided with complete normalisation of the ST segments (black arrows).

stratify for sudden cardiac arrest/death. However, exercise testing can result in ST segment depression that in the presence of delta wave are generally felt to be a false positive finding. These abnormal ST segment changes are due to conduction over the 
accessory pathway that result in aberrant depolarisation and repolarisation. ${ }^{3}$ The ST segment depression generally normalise after loss of the delta wave and with the return of normal ventricular repolarisation via the His-Purkinje system. ${ }^{4}$ Thus, in circumstances when the delta wave and concomitant ST segment depression persist throughout maximal effort stress testing, an individualised approach should be taken to determine the need

\section{Patient's perspective}

When I found out I had WPW it was quite a shock. I've been active all of my life and elevated my heart rate countless time with no problems. It was frustrating at the time because the diagnosis prevented me from playing rugby for a couple of weeks, but the ablation procedure was quick and recovery was instantaneous.

\section{Learning points}

- Exercise testing in athletes with Wolff-Parkinson-White pattern can result in ST segment depression that in the presence of delta wave are generally felt to be a false positive finding.

- The abnormal ST segment changes are due to conduction over the accessory pathway that result in aberrant depolarisation and repolarisation.

- After loss of the delta wave, normal ventricular repolarisation via the His-Purkinje system returns and coincides with normalisation of the ST segments. for further risk stratification to assess for ischaemia. However, when loss of the delta wave near peak exercise is accompanied by complete resolution of the ST segment depression, further risk stratification is generally not warranted as the ST segment normalisation confirms a false positive finding.

Twitter Arjun Kanwal @arjun.kanwa

Contributors All authors have participated in the work and have reviewed and agreed with the content of the article. All four authors have helped with writing and editing the manuscript. They helped with editing and creating the images. AK was the lead author on the writing of the manuscript. ABS helped to write and edit the manuscript. $A B S$ was also involved with image editing. KMB was the primary lead on organisation of the manuscript. BED was involved in manuscript editing and image acquisition. All four authors had direct patient interaction. AK reached out to the patient for consent.

Funding The authors have not declared a specific grant for this research from any funding agency in the public, commercial or not-for-profit sectors.

Competing interests None declared.

Patient consent for publication Obtained.

Provenance and peer review Not commissioned; externally peer reviewed.

\section{ORCID iD}

Arjun Kanwal http://orcid.org/0000-0002-6370-289X

\section{REFERENCES}

1 Baggish AL, Shah AB. My approach to the athlete with Wolff-Parkinson-White syndrome (WPW). Trends Cardiovasc Med 2018;28:154-5.

2 Harmon KG, Asif IM, Maleszewski JJ, et al. Incidence, cause, and comparative frequency of sudden cardiac death in national collegiate athletic association athletes: a decade in review. Circulation 2015;132:10-19.

3 Shah PP, Nair M, Dhall A, et al. False-Positive exercise stress electrocardiogram due to accessory pathway in the absence of manifest preexcitation. Pacing Clin Electrophysiol 2000;23:1051-3.

4 Jezior MR, Kent SM, Atwood JE. Exercise testing in Wolff-Parkinson-White syndrome. Chest 2005;127:1454-7.

Copyright 2020 BMJ Publishing Group. All rights reserved. For permission to reuse any of this content visit

https://www.bmj.com/company/products-services/rights-and-licensing/permissions/

BMJ Case Report Fellows may re-use this article for personal use and teaching without any further permission.

Become a Fellow of BMJ Case Reports today and you can:

- Submit as many cases as you like

- Enjoy fast sympathetic peer review and rapid publication of accepted articles

- Access all the published articles

- Re-use any of the published material for personal use and teaching without further permission

Customer Service

If you have any further queries about your subscription, please contact our customer services team on +44 (0) 2071111105 or via email at support@bmj.com.

Visit casereports.bmj.com for more articles like this and to become a Fellow 